\title{
Wiedemann-Rautenstrauch neonatal progeroid syndrome: report of three new patients
}

\author{
Humberto Arboleda, Luis Quintero, Emilio Yunis
}

\begin{abstract}
Wiedemann-Rautenstrauch (WR) syndrome is known as a neonatal progeroid syndrome, with only few published case reports. We describe three additional patients, two of them sibs, showing the clinical features of WR syndrome. Skeletal abnormalities are reported and assays of hormones and lipids are presented in one patient. Disturbance in bone maturation and lipid and hormone metabolism appear to be involved in this neonatal progeroid syndrome.

(f Med Genet 1997;34:433-437)
\end{abstract}

Keywords: neonatal progeroid syndrome; WiedemannRautenstrauch syndrome; autosomal recessive disorder; bone maturation-lipid-hormone

Instituto de Genética, Universidad Nacional de Colombia, Santafé de Bogotá, Colombia H Arboleda

L Quintero

E Yunis

Correspondence to:

Dr Arboleda.

Received 15 August 1996 Revised version accepted for publication 4 December 1996
Physical examination at birth showed apparent macrocephaly with frontal and biparietal bossing, large fontanelles and wide sutures, sparse scalp hair, and prominent scalp veins; hypoplasia of the facial bones, small and beak shaped nose; upward slanting palpebral fissures; hypertelorism, sparse eyebrows and eyelashes; and very low set, small, dysplastic ears with absent lobes. The mouth, with one incisor, was small and retracted, with a small linear dimple below the lower lip; the chin was sharp and pointed. All these features conferred a progeroid appearance to the patient (fig 2A, B).

The thorax showed a broad base and there were no cardiac murmurs. The external genitalia were of a normal female. The limbs were slender with flexed articulations and the hands and feet appeared large. There was generalised deficient subcutaneous fat, with the exception of excessive fat on the buttocks. The skin was thin, dry, and shiny. She was hypertonic and died at 2 weeks of an undetermined cause.

Radiographs showed craniofacial disproportion and severe dysostosis. The ilia were hypoplastic with a trident configuration of the acetabula, the metaphyseal end plates of the long bones, mainly the femora and tibiae, were irregular, and the diaphyses were thin (fig $3 \mathrm{~A}$, table 2). Chromosome study showed a normal karyotype, 46,XX.

Table 1 Clinical features in Wiedemann-Rautenstrauch syndrome. Comparison of the features of our patients with previously reported cases

\begin{tabular}{|c|c|c|c|c|c|c|c|c|c|c|c|c|c|c|}
\hline \multirow[b]{3}{*}{ Birth weight (g) } & \multirow{2}{*}{\multicolumn{2}{|c|}{ Wiedemann ${ }^{2}$}} & \multirow{2}{*}{\multicolumn{2}{|c|}{$\begin{array}{l}\text { Rautenstrauch } \\
\text { et al }\end{array}$}} & \multirow{3}{*}{$\begin{array}{l}\begin{array}{l}\text { Devos } \\
e^{2 t} \mathrm{ll}^{3}\end{array} \\
2110\end{array}$} & \multirow{3}{*}{$\begin{array}{l}\begin{array}{l}\text { Rudin } \\
\text { et }^{5} l^{5}\end{array} \\
2500\end{array}$} & \multirow{3}{*}{$\begin{array}{l}\begin{array}{l}\text { Obregon } \\
\text { et al }\end{array} \\
2300\end{array}$} & \multirow{3}{*}{$\begin{array}{l}\text { Castiñeyra } \\
\text { et al }\end{array}$} & \multirow{3}{*}{$\begin{array}{l}\begin{array}{l}\text { Bitoun } \\
\text { et } a l^{8}\end{array} \\
1950\end{array}$} & \multirow{2}{*}{\multicolumn{2}{|c|}{ Leroy et al }} & \multicolumn{3}{|c|}{ Present report } \\
\hline & & & & & & & & & & & & \multirow{2}{*}{$\begin{array}{l}1 \\
1500\end{array}$} & \multirow{2}{*}{$\frac{2}{1700}$} & \multirow{2}{*}{$\frac{3}{2120}$} \\
\hline & 2200 & 2550 & 2380 & 2110 & & & & & & 2150 & 1300 & & & \\
\hline Birth length $(\mathrm{cm})$ & 45 & 49 & 48 & 47 & 48 & 45 & NR & 47 & 42 & 45 & 34 & 43 & 45 & 47 \\
\hline Head circumference $(\mathrm{cm})$ & NR & NR & 32.5 & 32 & 33 & 34 & 36 & 31 & 35 & 31 & 28.5 & 29 & 30 & NR \\
\hline Sex & $\mathbf{M}$ & $\mathbf{M}$ & $\mathrm{F}$ & F & $\mathrm{F}$ & $\mathbf{M}$ & $\mathrm{F}$ & $\mathrm{F}$ & $\mathbf{M}$ & $\mathbf{F}$ & $\mathbf{M}$ & F & $\mathbf{M}$ & $\mathbf{M}$ \\
\hline Consanguinity & - & - & - & - & + & - & - & - & + & - & - & - & - & - \\
\hline Senile aspect & + & + & + & + & + & + & + & + & + & + & + & + & + & + \\
\hline Wide open sutures & + & + & + & + & + & + & + & + & + & NR & NR & + & + & + \\
\hline Widened fontanelles & + & + & $+?$ & + & + & $+?$ & NR & + & + & + & + & + & + & + \\
\hline Sparse scalp hair & + & + & + & + & + & + & + & + & - & - & NR & + & + & + \\
\hline Prominent scalp veins & + & + & + & + & + & + & + & + & + & + & NR & + & + & + \\
\hline Hypoplasia of the facial bones & + & + & + & + & + & + & + & + & + & NR & NR & + & + & + \\
\hline Low set ears & + & + & + & + & + & + & + & NR & + & + & NR & + & + & + \\
\hline Beak shaped nose & + & + & + & + & + & + & + & + & - & $+?$ & NR & + & + & + \\
\hline Intraocular abnormalities & - & - & - & - & - & - & - & NR & - & - & - & - & - & - \\
\hline Dentition present at birth & 2 & 4 & 2 & 2 & 1 & 4 & 2 & 2 & - & - & - & 1 & 4 & 4 \\
\hline Slender limbs & + & + & + & + & + & + & + & + & + & - & - & + & + & + \\
\hline Hypertonia & NR & NR & NR & NR & NR & NR & NR & NR & - & - & NR & + & + & + \\
\hline Prepucial hypoplasia & NR & NR & & & & NR & & & - & NR & NR & & + & + \\
\hline Large penis & + & + & & & & NR & & & - & NR & NR & & - & - \\
\hline Cryptorchidism & NR & NR & & & & + & & & - & NR & NR & & + & + \\
\hline Gynaecomastia & NR & NR & NR & NR & NR & NR & NR & NR & - & - & NR & - & + & - \\
\hline Fat accumulation in buttocks & + & + & NR & NR & + & + & + & + & - & - & NR & + & - & NR \\
\hline
\end{tabular}

NR: not reported. 


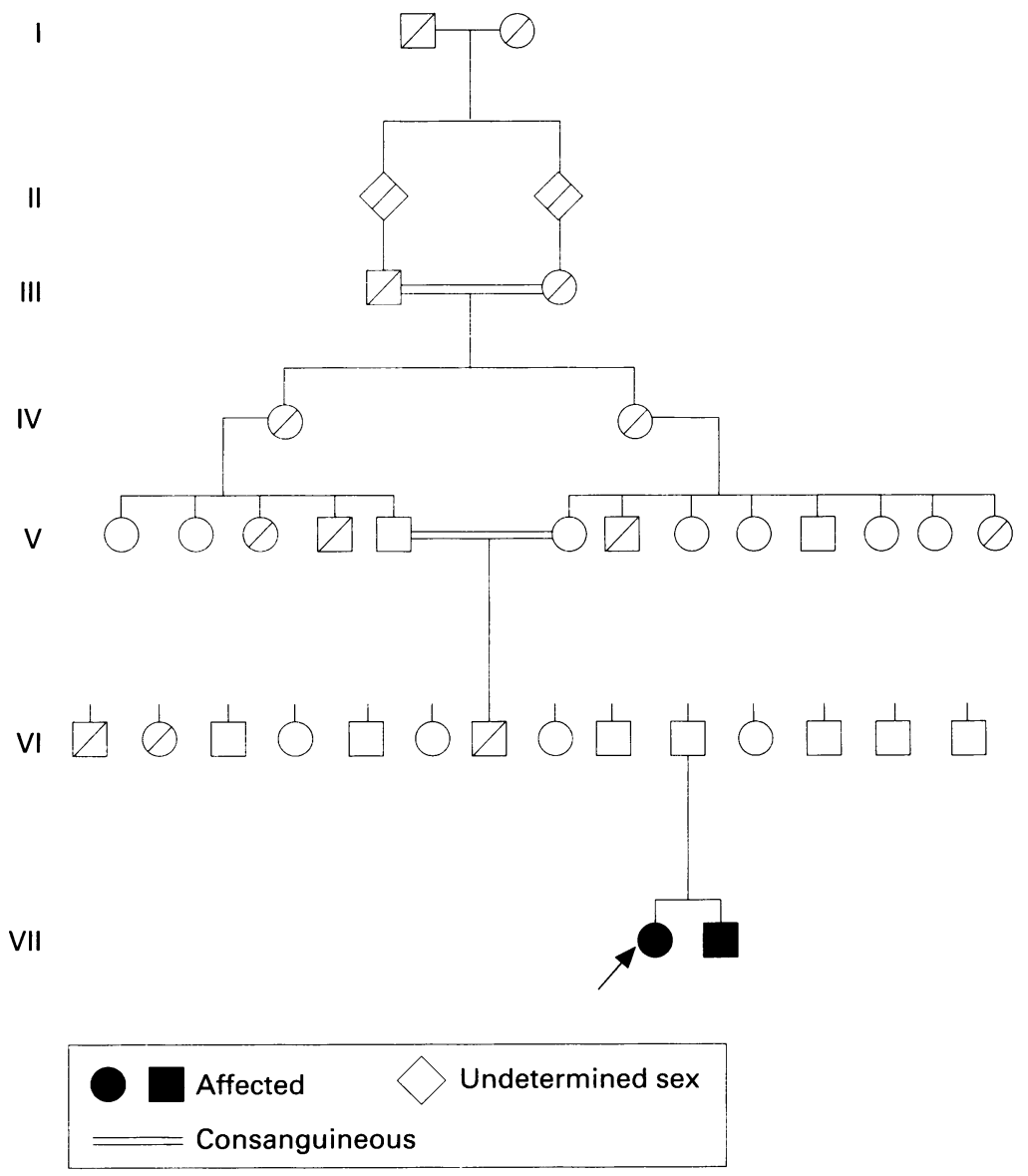

Figure 1 Family pedigree of cases 1 and 2.

CASE 2

Case 2 was the brother of patient 1 and was the product of the second pregnancy, three years after the first. Pregnancy was normal and vagi- nal delivery was at term. Table 1 shows the clinical features of this patient.

A progeroid appearance was evident with frontal and parietal bossing, wide sutures and large fontanelles, almost total alopecia, and small capillary haemangiomas in the metopic, interparietal, and occipital regions. Prominent scalp veins were present (fig $2 \mathrm{C}$ ). There was craniofacial disproportion with small facial bones, depressed frontonasal angle, ocular proptosis, small, beak shaped nose, small and low set ears with a normal configuration, a downward slanting mouth with four teeth, two yellowish maxillary and two mandibular incisors, and a V shaped palate. There was evident gynaecomastia without milk secretion, a short prepuce, and bilateral cryptorchidism.

The extremities appeared thin, with long hands and feet (fig 2D), stiff articulations, and prominent muscle mass and venous circulation. In general, the skin was thin and hyperaemic, with deficient subcutaneous fat. The finger and toenails were normal.

Ophthalmic examination showed normal anterior poles, clear lens and vitreous, and hypopigmented fundi. Neurologically he was hypertonic and his cry was weak.

Results of lipid determination are shown in table 3 . Hormone assays showed high levels of prolactin $(140 \mathrm{ng} / \mathrm{ml}$, normal values $(\mathrm{NV})<15$ $\mathrm{ng} / \mathrm{ml})$, testosterone $(2.4 \mathrm{ng} / \mathrm{ml}, \mathrm{NV}<0.1$ $\mathrm{ng} / \mathrm{ml})$, oestradiol $(107 \mathrm{pg} / \mathrm{ml}, \mathrm{NV} 3-10 \mathrm{pg} / \mathrm{ml})$, and T4 $(19.3 \mu \mathrm{g} / 100 \mathrm{ml}, \mathrm{NV} 7.3-15 \mu \mathrm{g} / 100$ $\mathrm{ml})$. TSH analysis gave results within normal limits $(0.65 \mu \mathrm{IU} / \mathrm{ml}$, NV 0.5-5 $\mu \mathrm{IU} / \mathrm{ml})$; T3 assay was not reported. Chromosome study showed a normal karyotype, $46, \mathrm{XY}$.

Failure to thrive was evident one month later and the same clinical features were present at 6
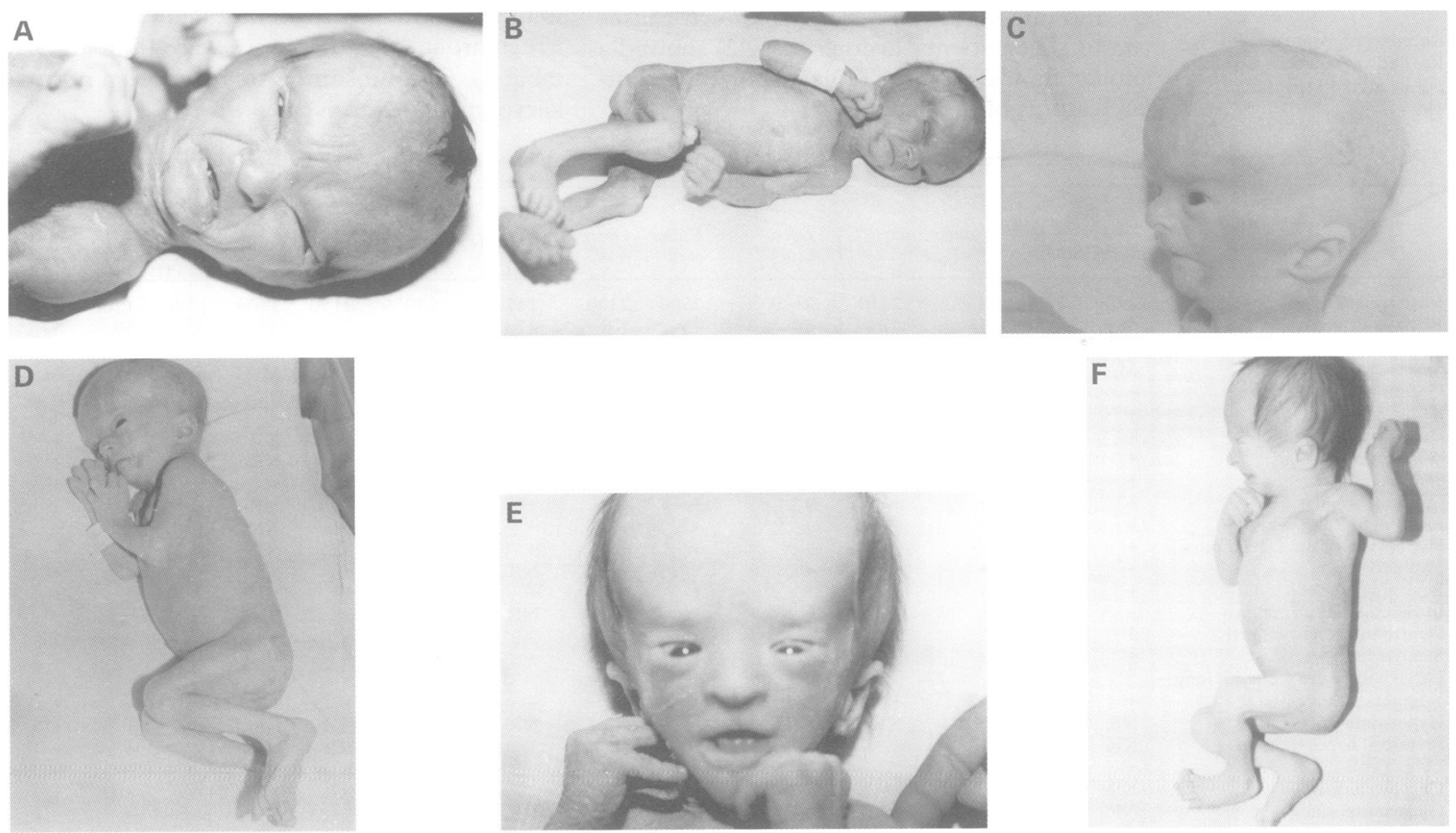

Figure 2 Photographs of the three patients, at birth (case 1), 5 months (case 2), and 8 days after birth (case 3). (A, B) Case 1. (C, D) Case 2. (E, F) Case 3. 

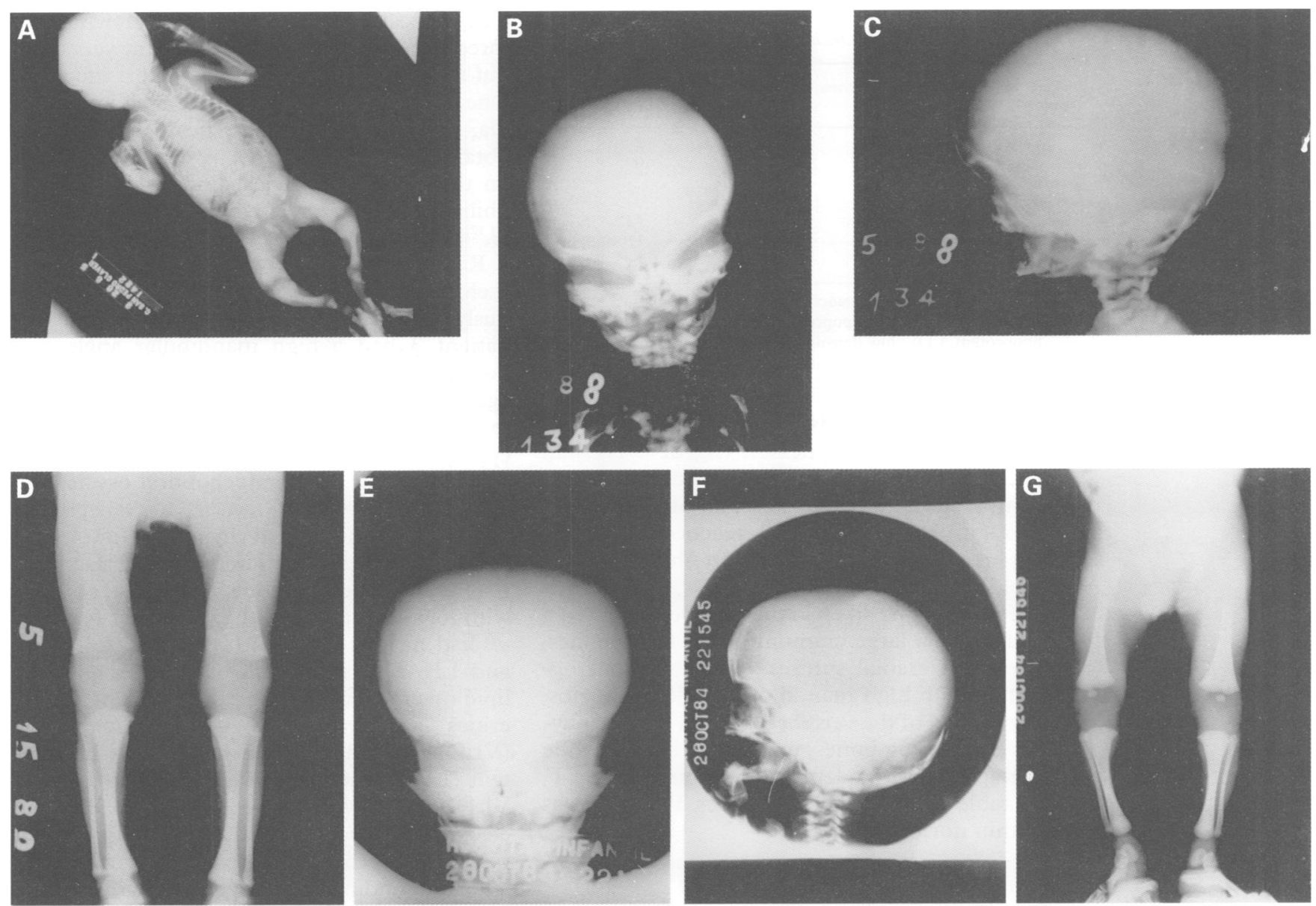

Figure $3 X$ rays of the three patients, at birth (case 1), 5 months (case 2), and 8 days after birth (case 3). (A) Case 1. (B, C, D) Case 2. (E, F, G) Case 3.

months of age with global hypotrophy and slow psychomotor development. There was no accumulation of adipous tissue in the lumbosacral area.

Radiographs showed craniofacial disproportion, large sutures and fontanelles with evident severe dysostosis, frontal and parietal bossing, elongated orbits, global hypoplasia of the facial bones, and thin long bones with enlarged metaphyseal end plates in the femora and tibiae (fig 3B, C, D, table 2). At the age of 6 months, bone age was 3 months; by then the patient was in hospital with leucoplastic keratitis and pneumonia which led to his death.

CASE 3

This male was the second child of healthy, young, unrelated parents (mother 21 and father 25 years old); pregnancy and delivery were normal. His older brother is healthy.
Physical examination at 8 days showed (table 1): apparent macrocephaly with frontal and parietal bossing, wide sutures and fontanelles, alopecia, and prominent scalp veins. The face appeared progeroid and triangular with a depressed nasal bridge, small, beak shaped nose with thin skin, upward slanting palpebral fissures with epicanthic folds, prominent lower eyelids, blue sclerae, and alopecia of the eyebrows and eyelashes. He had right sided esotropia, low set ears with square lobes, a long philtrum, thin lips, a pointed chin, and a high palate (table 1). There were four natal teeth, lost during the first week of life (fig $2 \mathrm{E}$ ).

The neck was short with redundant skinfolds and the chest was short and showed a broad base without cardiac murmurs or abdominal visceromegaly. There was gynaecomastia, hypoplastic prepuce, and cryptorchidism. The limbs were thin with enlarged and rigid articu-

Table 2 Radiographic findings in Wiedemann-Rautenstrauch syndrome. Comparison of 13 patients

\begin{tabular}{|c|c|c|c|c|c|c|c|c|c|c|c|c|c|}
\hline \multirow[b]{2}{*}{ Patient No } & \multicolumn{2}{|c|}{ Wiedemann ${ }^{2}$} & \multicolumn{2}{|c|}{ Rautenstrauch et al ${ }^{l}$} & \multirow[t]{2}{*}{ Devos et $a l^{3}$} & \multirow[t]{2}{*}{$\begin{array}{l}\text { Rudin } \\
\text { et } a l^{5}\end{array}$} & \multirow[t]{2}{*}{$\begin{array}{l}\text { Obregon } \\
\text { et al }\end{array}$} & \multirow[t]{2}{*}{$\begin{array}{l}\text { Bitoun } \\
\text { et al }^{8}\end{array}$} & \multicolumn{2}{|c|}{ Leroy et al ${ }^{\prime}$} & \multicolumn{3}{|c|}{ Present report } \\
\hline & 1 & 2 & 1 & 2 & & & & & 1 & 2 & 1 & 2 & 3 \\
\hline Large skull & + & + & + & + & + & + & + & + & - & - & + & + & + \\
\hline Small facial bones & + & + & + & + & & + & + & + & & & + & + & + \\
\hline Wide cranial sutures & + & + & + & + & & + & + & + & & & + & + & + \\
\hline Partly unossified atlas & & & & & & + & + & & & & & + & + \\
\hline Thin ribs & & & & & & & + & - & + & + & + & + & + \\
\hline Hypoplasia of vertebral bodies & & & & & & & + & - & + & + & + & & + \\
\hline Trident configuration of the acetabula & & & & & & + & + & - & & & + & & + \\
\hline Unossified ischia & & & & & & + & + & - & & & + & & + \\
\hline Irregular end plates of the metaphyses & & & & & & + & + & - & + & + & + & & - \\
\hline
\end{tabular}


Table 3 Comparison of lipids in three patients with Wiedemann-Rautenstrauch syndrome

\begin{tabular}{llll}
\hline & $\begin{array}{l}\text { Rautenstrauch } \\
\text { et al }\end{array}$ & Rudin et al $^{5}$ & Present report \\
\hline Patient* & 2 & & 2 \\
Age (y) & 4 & 0 & 0 \\
Cholesterol & $\mathrm{N}$ & $\mathrm{N}$ & \\
Triglycerides & & $\mathrm{H}$ & \\
HDL & $\mathrm{N}$ & $\mathrm{N}$ & $\mathrm{L}(7.4) \dagger$ \\
VLDL & $\mathrm{N}$ & $\mathrm{H}$ & $\mathrm{H}(89.3) \dagger$ \\
LDL & $\mathrm{N}$ & $\mathrm{L}$ & $\mathrm{L}(3.3) \dagger$ \\
\hline
\end{tabular}

* Patients 2 of Rautenstrauch et al ${ }^{\prime}$ and present report.

HDL: high density lipoprotein, VLDL: very low density lipoprotein, LDL: low density lipoprotein.

$\mathrm{N}$ : normal range, $\mathrm{H}$ : high range, $\mathrm{L}$ : low ranges.

† Percentage by electrophoresis.

lations and the hands and feet were large with arachnodactyly and flexion (fig $2 \mathrm{~F}$ ). He had rocker bottom feet. The skin was dry, thin, and shiny with generalised absence of subcutaneous fat. He had normal reactions but was hypertonic. Chromosome study showed a normal karyotype, 46,XY.

Radiographs taken in the first week showed a skull with a large cranium, small facial bones, and wide cranial sutures. There was micrognathia with high mandibular angles, thin ribs, hypoplasia of the vertebral bodies, thin diaphyses of the long bones, mainly the fibulae, wide metaphyses of the femora and tibiae (fig $3 \mathrm{E}, \mathrm{F}$, $\mathrm{G}$, table 2), and small iliac bones. Bone age was within normal limits.

\section{Discussion}

Wiedemann-Rautenstrauch syndrome is recognised as a neonatal progeroid syndrome. Ten cases have been reported so far, ${ }^{1-8}$ and another two patients were reported at a clinical genetics meeting. ${ }^{9}$

This syndrome was delineated as a new progeroid syndrome by Wiedemann ${ }^{2}$ based on two personal observations and two sisters reported by Rautenstrauch and Snigula. ${ }^{1}$ The major physical features remain unchanged in survivors. ${ }^{1011}$ Evidence for an autosomal recessive pattern of inheritance has been presented in four reports, ${ }^{1378}$ with possibilities of prenatal diagnosis by ultrasound. ${ }^{8}$

We describe three additional patients, two of them sibs, providing further evidence for this pattern of inheritance. The striking resemblance to the previously reported children with the Wiedemann-Rautenstrauch syndrome is obvious in our three patients.

Patients with this syndrome can be recognised at birth because of a wide spectrum of abnormalities (table 1), among which are short stature, failure to thrive, progeroid appearance, apparent macrocephaly with frontal and parietal bossing, wide fontanelles and sutures, prominent scalp veins, hypoplasia of the facial bones, sparse scalp hair, eyebrows, and eyelashes, and generalised lipoatrophy. Most patients showed neonatal teeth, which were lost early. In one patient we found gynaecomastia without milk secretion; case 2 and case 3 had cryptorchidism and short prepucial folds.

The majority of these patients die during the first days or months after birth. Two of our patients survived for two and six months. The date of death of the third is not known. Only three patients have survived for some years, ${ }^{6811}$ but the other cases have had a short life span. One of our patients died of bronchopneumonia. Because no pathological details were obtained in these patients, we cannot comment on the neuropathological findings of sudanophilic leucodystrophy reported by Martin et $a .^{12}$

Radiographs of our three patients showed skeletal abnormalities that have been previously described ${ }^{6}$ (table 2). In addition, our patient 3 had a high mandibular angle and bone age in agreement with his chronological age. Moreover, it appeared that dysostosis involved the metaphyseal area more than the epiphyseal. Nevertheless we think that membranous rather than endochondral ossification is involved.

One case developed hypothyroidism. ${ }^{8}$ At birth our patient 2 showed hyperprolactinaemia and high testosterone, oestradiol, and T4, with low normal TSH; the patient of Rudin et $a t$ had normal levels of $\mathrm{HGH}$, cortisol, FSH, and LH. However, both had disturbances in lipid metabolism, with increased serum triglycerides and very low density lipoprotein (VLDL) and diminished low density lipoprotein (LDL) fraction in the former, and raised VLDL and low levels of LDL and HDL in electrophoretic assays in the second. In another patient ${ }^{1}$ lipoproteins were in the normal range. The lipid findings in these patients are summarised in table 3. Deficient biosynthesis of decorin has been reported, although this is a non-specific and probably secondary phenomenon. ${ }^{9}$ As in the other previously published cases, peripheral lymphocyte chromosomes were normal in number and structure in our patients.

The aetiology of Wiedemann-Rautenstrauch syndrome is still unclear; it has been stated that it is not a malformation syndrome, but a disorder that involves mesenchymal tissue, mainly subcutaneous fat. ${ }^{3}$ Our findings implicate a disturbance in the mechanism of bone maturation as well as lipid and hormone metabolism.

1 Rautenstrauch T, Snigula F. Progeria: a cell culture study and clinical report of familial incidence. Eur $\mathcal{f}$ Pediatr 1977;124:101-11.

2 Wiedemann HR An unidentified neonatal progeroid syndrome: follow-up report. Eur $\mathcal{F}$ Pediatr 1979;130:65-70.

3 Devos EA, Leroy JG, Fryns JP, Van den Berghe H. The Wiedemann-Rautenstrauch or neonatal progeroid syndrome. Report of a patient with consanguinous parents. Eur $\mathcal{F}$ Pediatr 1981;136:245-8.

4 Ohashi H, Eguchi T, Kajii T. Neonatal progeroid syndrome: report of a Japanese infant. Fpn f Hum Genet 1987;32:253. 5 Rudin C, Thommen L, Fliegel C, Steinmann B, Buhler U. The neonatal pseudo-hydrocephalic progeroid syndrom Wiedemann-Rautenstrauch). Report of a new patient an review of the literature. Eur f Pediatr 1988;147:433-8.

6 Obregon MG, Bergami GL, Giannotti A, et al. Radiographic findings in Wiedemann-Rautenstrauch syndrome. Pediatr Radiol 1992;22:474-5.

7 Castiñeyra G, Panal M, Lopez H, Goldschmidt E, Sanchez JM. Two sibs with Wiedemann-Rautenstrauch syndrome: possibilities of prenatal diagnosis by ultrasound. $\mathcal{F}$ Med gonsilities $1992 ; 29: 434-6$.

8 Bitoun P, Lachassine E, Sellier N, Sauvion S, Gaudelus J. Bitoun P, Lachassine E, Sellier N, Sauvion S, Gaudelus J. The Wedemann-Rautenstrauch neonatal progeroid Dysmorphol $1995 ; 4: 239-45$.

9 Leroy JG, Beavan LA, Quentin-Hoffman E, Kresse H. Deficient decorin biosynthesis in the neonatal progeroid syndrome. In: Bartsocas CS, Beighton P, eds. Dysmorphol- 
ogy and genetics of cardiovascular disorders. Chapter 24 Athens: HTA Medical Publication, 1994:166-76.

10 Snigula F, Rautenstrauch T. A new neonatal progeroid syndrome. Eur f Pediatr 1981;136:325.

11 Rautenstrauch T, Snigula F, Wiedemann HR. Neonatales progeroides Syndrom (Wiedemann-Rautenstrauch). Eine
follow-up-Studie. Klin Padiatr 1994;206:440-3.

12 Martin JJ, Ceuterick CM, Leroy JG, Devos EA, Roelens JG. The Wiedemann-Rautenstrauch or neonatal progeroid syndrome. Neuropathological study of a case. Neuropediatrics 1984;15:43-8. 